\title{
OTTO SZÁSZ
}

On September 19, 1952, Otto Szász, Professor at the University of Cincinnati, died in his 68th year. Szász was a native of Hungary, studied in Budapest, Göttingen, Munich and Paris, and received his Ph.D. degree at the University of Budapest in 1911. He was Privatdozent (later with the title of a professor) at the University of Frankfurt, Germany, from 1914 until 1933. He was also Privatdozent at the University of Budapest. In 1933 he came to the United States, first to the Massachusetts Institute of Technology and Brown University and in 1936 to the University of Cincinnati where he resided until his death. The only interruption of his stay at this university was a year spent with the Institute of Numerical Analysis at the University of California in Los Angeles. In 1930 Szász received the Julius König prize of the Hungarian Mathematical and Physical Society. He was a member of the American Mathematical Society and of the Mathematical Association of America.

The life of Szász was spent in deep devotion to mathematical study, research and teaching. His steady preoccupation with mathematics, his erudition and broad knowledge of classical and contemporary literature and his perseverance in dealing with open problems of a number of varied fields have secured a firm place for him in the mathematical life of Hungary, Germany and of the United States. He inspired many young persons and collaborated with numerous mature mathematicians. He maintained warm and mathematically fruitful relations with such great personalities as Fejér, Landau, Perron, Pringsheim and I. Schur. The short résumé of his most important accomplishments to be given below reflects these relationships.

We can distinguish various periods in the work of Szász. Economy of space compels us to quote (by numbers in brackets) only a few of his papers enumerated at the end of this note.

1. Continued fractions. The work of Szász in this direction deals with convergence questions $[5 ; 8]$ generalizing certain results of Perron. Another paper deals with the special case of continued fractions of the Stieltjes-A. Markov type [2] answering a conjecture of Perron. Finally [1] is concerned with the irrational character of certain continued fractions.

2. Approximations $[3 ; 6]$. These contributions are related to the famous problem of $\mathrm{S}$. Bernstein solved by $\mathrm{Ch}$. H. Müntz about the completeness of a set of powers $x^{p_{n}}$ in a finite positive interval. 
3. Bounded power series. This work was inspired by the problem of Landau to determine the maximum modulus of the $n$th partial sum of those power series $f(z)$ which are regular in the unit circle and for which $|f(z)|<1$ in $|z|<1$ holds. Szász gives various far-reaching generalizations of the result of Landau [7]. ${ }^{1} \mathrm{His}$ further contributions in this direction are connected, among others, with a related problem of F. Riesz.

4. Trigonometric polynomials. These papers $[10 ; 12]$ deal with inequalities for the coefficients of trigonometric polynomials subjected to various conditions of boundedness. Another particularly interesting result of Szász [4] is the following inequality for a non-negative trigonometric polynomial $\sum c_{\nu} e^{i \nu x},-n \leqq \nu \leqq n$ :

$$
\sum\left|c_{\nu}\right| \leqq(n+1) c_{0},
$$

with equality for the Fejer means $c_{\nu}=1-|\nu| /(n+1)$. We mention also [7] a very simple proof for the theorem of M. Riesz (in fact of S. Bernstein) on the derivative of a rational polynomial which remains under a given bound in the unit circle.

5. Fourier series. Probably the most interesting contribution of Szász [11] to this field is the refinement of certain results of S. Bernstein and Hardy-Littlewood concerning the sum $\sum\left|c_{n}\right|^{k}$ where $c_{n}$ denotes the Fourier coefficients of a given periodic function $f(x)$. Assuming that the mean value

$$
\left\{\frac{1}{2 \pi} \int_{-\pi}^{\pi}|f(u+h)-f(u)| p d u\right\}^{1 / p}
$$

is of the order $|h|^{\alpha}, 1<p \leqq 2,0<\alpha<1$, Szász proves that the sum in question is convergent provided $k>p(p \alpha+p-1)^{-1}$ and this bound is in a certain sense the best possible. Other theorems deal with the order of approximation by Fejér means connected again with certain results of S. Bernstein [9].

Further remarkable contributions of Szász are concerned with Tauberian theorems, various methods of summability, Gibbs phenomenon, etc. Many of the papers from the last period of his life (after 1933) are devoted to these subjects. He contributed, jointly with E. Hilb, to the Encyclopedia of Mathematics by an article dealing with expansions in terms of functions of a complex variable.

His students and friends will always warmly remember him as a

1 These generalizations turned out to be useful in the investigations of W. Rogosinski-G. Szegö, Math. Zeit. vol. 28 (1928). 
man of gentle, unassuming and quiet personality. His life and energy were dedicated to the promotion of simple and beautiful problems of Mathematics, in particular of the classical Analysis. His nearly one hundred and thirty mathematical papers remain a living document of his efforts.

\section{BIBLIOGRAPHY}

1. Ueber die Irrationalität unendlicher Kettenbrïche mit einer Anwendung auf die Reihen (with F. Bernstein), Math. Ann. vol. 76 (1915) pp. 295-300.

2. Bemerkungen zu Herrn Perrons Erweiterung eines Markoffschen Satzes ïber die Konvergenz gewisser Kettenbrïche, Math. Ann. vol. 76 (1915) pp. 301-314.

3. Ueber die Approximation stetiger Funktionen durch lineare Aggregate von Potenzen, Math. Ann. vol. 77 (1916) pp. 482-496.

4. Ueber nichtnegative trigonometrische Polynome, Sitzungsberichte der Bayerischen Akademie der Wissenschaften, Mathematisch-physikalische Klasse 1917, pp. 307-320.

5. Ueber die Erhaltung der Konvergenz unendlicher Kettenbrüche bei independenter Veränderlichkeit aller ihrer Elemente, J. Reine Angew. Math. vol. 147 (1917) pp. 132160.

6. Ueber die Approximation stetiger Funktionen durch Bernoullische Polynome, J. Reine Angew. Math. vol. 148 (1918) pp. 183-188.

7. Ungleichungen für die Koeffizienten einer Potenzreihe, Math. Zeit. vol. 1 (1918) pp. 163-183.

8. Ueber unendliche Kettenbrïche mit komplexen Elementen, Sitzungsberichte der Bayerischen Akademie der Wissenschaften, Mathematisch-physikalische Klasse 1919, pp. 395-406.

9. Ueber Fouriersche Reihen, Jber. Deutschen Math. Verein. vol. 32 (1923) pp. 194-198.

10. Elementare Extremalprobleme über nichtnegative trigonometrische Polynome, Sitzungsberichte der Bayerischen Akademie der Wissenschaften, Mathematischphysikalische Klasse 1927, pp. 185-196.

11. Ueber die Fourierschen Reihen gewisser Funktionenklassen, Math. Ann. vol. 100 (1928) pp. 530-536.

12. Einige Extremalprobleme im Bereiche der trigonometrischen Polynome (with E. von Egerváry), Math. Zeit. vol. 27 (1928) pp. 641-652.

GABOR SzeGö 